\title{
Factors associated with unreported tuberculosis cases in Spanish hospitals
}

\author{
Concepción Morales-García ${ }^{1,2^{*}}$, Teresa Rodrigo ${ }^{1,3,10}$, Marta M. García-Clemente ${ }^{1,4}$, Ana Muñoz ${ }^{1,5 \dagger}$, Pilar Bermúdez ${ }^{1,5 \dagger}$, \\ Francisco Casas ${ }^{1,6}$, María Somoza ${ }^{1,7}$, Celia Milá1,8, Antón Penas ${ }^{1,9}$, Carmen Hidalgo ${ }^{1,2}$, Martí Casals , $^{1,10}$, \\ Joan A. Caylá 10,11 and Working Group on Under-reporting of Tuberculosis in Spain
}

\begin{abstract}
Background: Under-reporting of tuberculosis (TB) cases complicates disease control, hinders contact tracing and alters the accuracy of epidemiological data, including disease burden. The objective of the present study is to evaluate the proportion of unreported TB cases in Spanish healthcare facilities and to identify the associated factors.

Methods: A multi-center retrospective study design was employed. The study included TB cases diagnosed in 16 facilities during 2011-2012. These cases were compared to those reported to the corresponding public health departments. Demographic, microbiological and clinical data were analyzed to determine the factors associated with unreported cases. Associated factors were analyzed on a bivariate level using the $x^{2}$ test and on a multivariate level using a logistic regression. Odds ratios (OR) and $95 \%$ confidence intervals (Cl) were calculated.

Results: Of the 592 TB cases included in the study, 85 (14.4\%) were not reported. The percentage of unreported cases per healthcare center ranged from 0-45.2\%. The following variables were associated to under-reporting at a multivariate level: smear-negative TB $(\mathrm{OR}=1.87$; $\mathrm{Cl}: 1.07-3.28)$, extrapulmonary disease $(\mathrm{OR}=2.07 ; \mathrm{Cl}: 1.05-4.09)$ and retired patients $(\mathrm{OR}=3.04 ; \mathrm{Cl}: 1.29-7.18)$. A nurse case manager was present in all of the centers with $100 \%$ reporting. The percentage of reported cases among the smear-positive cases was $9.4 \%$ and $19.4 \%(p=0.001)$ among the rest of the study population. Smear-positive TB was no associated to under-reporting.

Conclusions: It is important that TB Control Programs encourage thorough case reporting to improve disease control, contact tracing and accuracy of epidemiological data. The help from a TB nurse case manager could improve the rate of under-reporting.
\end{abstract}

Keywords: Notifications, Under-reporting, Reporting, Tuberculosis, Spain

\section{Background}

Tuberculosis (TB) continues to be an important public health problem worldwide. In 2013, 9 million people developed TB and 1.5 million people died from the disease [1]. An estimated three million people with TB in 2012, one third of the total cases, were not reported to a national surveillance system [1]. Prevention and control requires quick and systematic reporting of new

\footnotetext{
* Correspondence: concepcionmorales@telefonica.net

${ }^{\dagger}$ Equal contributors

${ }^{1}$ Programa Integrado de Investigación en Tuberculosis (PII-TB) de la Sociedad Española de Neumología y Cirugía Torácica (SEPAR), Barcelona, Spain ${ }^{2}$ Hospital Universitario Virgen de las Nieves de Granada, Granada, Spain Full list of author information is available at the end of the article
}

TB cases to surveillance centers to ensure treatment compliance and to facilitate contact tracing.

The incidence of reported TB cases in the European Union countries is 13.5 per 100,000 inhabitants [2] and is predominant among vulnerable populations [3]. Spain is considered a country of low TB incidence, with a rate of 14.7 cases per 100,000 in 2012 [2]. However, the distribution between different regions, or autonomous communities, is not equal, and ranges between 8 and 29 cases per 100,000 inhabitants [4].

The low TB incidence observed in Spain during recent years could be not only a result of disease control, but could also be a reflection of missed diagnoses or underreporting $[5,6]$. The potentially missed diagnoses or unreported cases would affect $\mathrm{TB}$ incidence in the country. 
This has been previously observed and published in other countries [6-12], but not well-studied in Spain. Data published on rate of unreported cases in Spain is limited to only one region [13-15], and was estimated at around $20 \%$ [13-16]. In Galicia and Barcelona, two areas with effective TB control programs, the TB incidence is higher than the national average. This may be also due to under-reporting in other parts of Spain.

Identifying factors that are associated with underreporting will allow us to target areas in need of better $\mathrm{TB}$ diagnosing and reporting, to in turn improve disease control. The objective of the present study is to describe the extent of unreported TB cases from healthcare facilities in various regions in Spain, and to identify the factors associated with unreported cases.

\section{Methods}

\section{Study design}

This is a multi-center, retrospective study on a cohort of TB cases diagnosed in 16 hospitals in Spain (Fig. 1) from January $1^{\text {st }}, 2011$ to December $31^{\text {st }}, 2012$. The study includes TB cases detected by microbiological, pathological and clinical records of each healthcare facility, which were then compared to cases registered by healthcare facilities at their corresponding public health departments, including the Public Health Department of Andalusia, Asturias, Catalonia, Cantabria, Galicia, The
Rioja, The Basque Country, Valencia and Madrid. Each case was classified as reported or not reported.

\section{Case definitions and data collection}

Clinical, microbiological, and pathological documents were obtained from each healthcare facility, in both electronic and paper form. The following criteria were used for pulmonary and extrapulmonary TB diagnosis: microbiological confirmation of Mycobacterium tuberculosis complex, pathology report compatible with TB (ie caseous granulomas by biopsy), or absence of microbiological confirmation but medically-deemed active TB by clinical and radiological findings. TB cases per healthcare facility records were linked to a list of TB cases provided by the corresponding public health department.

Unreported case was defined as a case that was detected in hospital records but not present in the TB registry of the corresponding public health department.

TB cases were classified as smear-positive, smearnegative or extrapulmonary, according to WHO criteria [17].

Clinical and epidemiological data was collected from patient records and registries, and stored in a database with electronic access using identifying information with a password for each of the study investigators.

The following variables were studied: socio-demographic data (age, sex, country of origin, employment, living



Fig. 1 Geographical location of the participating healthcare centers in the study 
situation, site of diagnosis and toxic habits), clinical data (HIV co-infection, history of previous TB treatment, disease involvement and radiographic findings), and microbiological data (smear, culture and anti-TB drug sensitivity results).

\section{Ethics}

The study was performed in accordance with the requirements stipulated in the Declaration of Helsinki (Tokyo revision, October 2004) and the Spanish Data Protection Act of 15/1999. The study was approved by the Independent Ethics Committees of the participating healthcare facilities (see Additional file 1).

\section{Statistical analysis}

Reported TB cases were classified as " 0 " and unreported cases as "1." The proportion of total unreported cases and proportion of unreported cases by healthcare facility were calculated. Absolute and relative frequencies were calculated for each variable and factors associated with unreported cases were analyzed on a bivariate level using the $\mathrm{x}^{2}$ test. A multivariate logistic regression model was constructed with the variables significant at the bivariate level, using manual stepwise selection to consider the factors with a $\mathrm{p}<0.05$ on a bivariate level. All variables without the presence of colinearity were included in the final model and interaction of covariates was evaluated.

Odds ratio (OR) and corresponding $95 \%$ confidence intervals $(\mathrm{CI})$ were calculated, and goodness of fit was tested using the Hosmer and Lemeshow test. $\mathrm{P}<0.05$ was considered statistically significant. IBM SPSS Statistics version 19.0 (SPSS Inc, Chicago, IL, USA) was used to perform all statistic analyses.

\section{Results}

Of the 592 TB cases diagnosed between 2011-12 at the 16 participating healthcare facilities (Table 1), 85 cases $(14.4 \%)$ were not identified in the public health department registries. This proportion ranged from 0 to $45.2 \%$ according to healthcare facility. One hundred percent of the TB cases from 5 healthcare facilities were reported to the corresponding public health department (all of which have a nurse case manager). The average of unreported cases was $20.7 \%$ among the other 11 healthcare facilities. Microbiological confirmation was present for 509 cases (86 \%).

The characteristics of the study population can be found in the Tables 2, 3 and 4. The majority of the cases presented with pulmonary or mixed TB, almost half were smear-positive, and more than one third presented with cavitation on chest $\mathrm{x}$-ray. One third of the patients were over 50 years of age and almost two thirds were between 18 and 50 years old (64.7\%). More than $20 \%$ of the cases lived alone, in a group, or were homeless, and $32.3 \%$ were
Table 1 Distribution of the diagnosis and reported of tuberculosis according to healthcare facilities

\begin{tabular}{|c|c|c|c|}
\hline \multirow[t]{2}{*}{ Healthcare facility } & \multicolumn{2}{|c|}{$\begin{array}{l}\text { Number of } \\
\text { tuberculosis cases }\end{array}$} & \multirow{2}{*}{$\begin{array}{l}\text { Total } \\
\text { (N / \%) }\end{array}$} \\
\hline & $\begin{array}{l}\text { Reported } \\
\text { (N / \%) }\end{array}$ & $\begin{array}{l}\text { Unreported } \\
(\mathrm{N} / \%)\end{array}$ & \\
\hline \multirow[t]{2}{*}{ Saint Millan-Saint Pedro Hospital } & 21 & 10 & 31 \\
\hline & $67.7 \%$ & $32.3 \%$ & $100.0 \%$ \\
\hline \multirow[t]{2}{*}{ Tarrasa Health Consortium } & 38 & 0 & 38 \\
\hline & $100.0 \%$ & $0.0 \%$ & $100.0 \%$ \\
\hline \multirow[t]{2}{*}{ Carlos III Hospital } & 18 & 7 & 25 \\
\hline & $72.0 \%$ & $28.0 \%$ & $100.0 \%$ \\
\hline \multirow[t]{2}{*}{ Xeral-Calde Hospital } & 29 & 5 & 34 \\
\hline & $85.3 \%$ & $14.7 \%$ & $100.0 \%$ \\
\hline \multirow[t]{2}{*}{ Castellon General Hospital } & 24 & 3 & 27 \\
\hline & $88.9 \%$ & $11.1 \%$ & $100.0 \%$ \\
\hline \multirow[t]{2}{*}{ Saint Agustin Hospital } & 17 & 14 & 31 \\
\hline & $54.8 \%$ & $45.2 \%$ & $100.0 \%$ \\
\hline \multirow[t]{2}{*}{ Sierrallana Hospital } & 27 & 1 & 28 \\
\hline & $96.4 \%$ & $3.6 \%$ & $100.0 \%$ \\
\hline \multirow[t]{2}{*}{ Carlos Haya Hospital } & 69 & 0 & 69 \\
\hline & $100.0 \%$ & $0.0 \%$ & $100.0 \%$ \\
\hline \multirow[t]{2}{*}{ Asturias Central Hospital } & 46 & 24 & 70 \\
\hline & $65.7 \%$ & $34.3 \%$ & $100.0 \%$ \\
\hline \multirow[t]{2}{*}{ Jaen Hospital } & 11 & 1 & 12 \\
\hline & $91.7 \%$ & $8.3 \%$ & $100.0 \%$ \\
\hline \multirow[t]{2}{*}{ Saint Boi Hospital } & 21 & 0 & 21 \\
\hline & $100.0 \%$ & $0.0 \%$ & $100.0 \%$ \\
\hline \multirow[t]{2}{*}{ Saint Ana Hospital } & 16 & 8 & 24 \\
\hline & $66.7 \%$ & $33.3 \%$ & $100.0 \%$ \\
\hline \multirow[t]{2}{*}{ Saint Marina Hospital } & 19 & 0 & 19 \\
\hline & $100.0 \%$ & $0.0 \%$ & $100.0 \%$ \\
\hline \multirow[t]{2}{*}{ Saint Cecilio Hospital } & 39 & 6 & 45 \\
\hline & $86.7 \%$ & $13.3 \%$ & $100.0 \%$ \\
\hline \multirow[t]{2}{*}{ Virgen de las Nieves Hospital } & 77 & 6 & 83 \\
\hline & $92.7 \%$ & $7.3 \%$ & $100.0 \%$ \\
\hline \multirow{2}{*}{$\begin{array}{l}\text { Prevention and Control Tuberculosis } \\
\text { Unit }\end{array}$} & 35 & 0 & 35 \\
\hline & $100.0 \%$ & $0.0 \%$ & $100.0 \%$ \\
\hline \multirow[t]{2}{*}{ TOTAL } & 507 & 85 & 592 \\
\hline & $85.6 \%$ & $14.4 \%$ & $100.0 \%$ \\
\hline
\end{tabular}

immigrants. More than half of the study population was diagnosed in the emergency department. Almost half (46.3\%) were smokers or ex-smokers, and around $20 \%$ were alcoholics. HIV co-infection was present in $4.2 \%$ of the population, although HIV status was unknown in $18.6 \%$ of the cases. Almost $6 \%$ of the TB cases were relapse. Four hundred and eleven $(69.5 \%)$ were diagnosed 
Table 2 Clinical and epidemiological characteristics of tuberculosis cases

\begin{tabular}{llll}
\hline & Total & Reported \\
\hline Variables & $\frac{N=592}{n}$ & $\frac{N=507}{n}$ & $\frac{n}{n}$
\end{tabular}

Age (years)

18-30

$31-50$

51-64

$>65$

Unknown

Sex

$$
\text { Male }
$$

Female

Unknown

Employment

Employed

Unemployed

Retired

Unknown/On disability

Living situation

With family

Alone

In a group

Homeless

Incarcerated

Unknown

Center of diagnosis

Emergency department

Primary care

Specialized center

Unknown or other

Smoking

Non-smoker
Smoker
Ex-smoker

Alcohol Use

Yes
No
Unknown

HIV status

Positive

Negative

Not known by patient

Unknown

$\begin{array}{llll}146 & 24.7 & 128 & 25,25 \\ 237 & 40 & 212 & 41,81 \\ 62 & 10.5 & 52 & 10,26 \\ 121 & 20.4 & 92 & 18,15 \\ 26 & 4.4 & 23 & 4,54\end{array}$

$368 \quad 62.2 \quad 321$

$214 \quad 36.1 \quad 179$

205

$34.6 \quad 174$

$184 \quad 31.1 \quad 169$

$\begin{array}{lll}78 & 13.2 \quad 70\end{array}$

$\begin{array}{lll}423 & 71.5 \quad 371\end{array}$

$\begin{array}{lll}42 & 7.1 \quad 33\end{array}$

$\begin{array}{lll}64 & 10.8 \quad 53\end{array}$

$\begin{array}{lll}14 & 2.4 & 11\end{array}$

$\begin{array}{lll}10 & 1.7 \quad 8\end{array}$

$\begin{array}{lll}39 & 6.6 \quad 31\end{array}$

$320 \quad 54.1 \quad 283$

$113 \quad 19.1 \quad 94$

$91 \quad 15.4 \quad 76$

$68 \quad 11.5 \quad 54$

$318 \quad 53.7 \quad 272$

$194 \quad 32.8 \quad 176$

80

$13.5 \quad 59$

$116 \quad 19.6 \quad 104$

$467 \quad 78.9 \quad 395$

$\begin{array}{lll}9 & 1.5 & 8\end{array}$

$25 \quad 4.2 \quad 23$

$446 \quad 75.3 \quad 384$

$110 \quad 18.6 \quad 91$

$11 \quad 1.9 \quad 9$

55,82 $\begin{array}{lll}10 & 1.7 \quad 7\end{array}$

$125 \quad 21.1 \quad 94$
Table 2 Clinical and epidemiological characteristics of tuberculosis cases (Continued)

\begin{tabular}{|c|c|c|c|c|}
\hline \multicolumn{5}{|l|}{ Previous tuberculosis treatment } \\
\hline No & 543 & 91.7 & 464 & 91,52 \\
\hline Yes & 34 & 5.7 & 29 & 5,72 \\
\hline Unknown & 15 & 2.5 & 14 & 2,76 \\
\hline \multicolumn{5}{|l|}{ Country of origin } \\
\hline Spain & 401 & 67.7 & 334 & 65,88 \\
\hline Other & 191 & 32.3 & 173 & 34,12 \\
\hline \multicolumn{5}{|l|}{ Drug resistance } \\
\hline No & 579 & 97.8 & 496 & 97,83 \\
\hline Yes & 13 & 2.2 & 11 & 2,17 \\
\hline \multicolumn{5}{|l|}{ Chest radiograph } \\
\hline Abnormal with cavitation & 208 & 35.1 & 191 & 37,67 \\
\hline Abnormal without cavitation & 284 & 48 & 235 & 46,35 \\
\hline Normal & 71 & 12 & 57 & 11,24 \\
\hline Unknown & 29 & 4.9 & 24 & 4,73 \\
\hline \multicolumn{5}{|l|}{ Microbiology } \\
\hline Smear-positive & 287 & 48.5 & 260 & 51,28 \\
\hline $\begin{array}{l}\text { Smear-negative and } \\
\text { culture-positive }\end{array}$ & 222 & 37.5 & 179 & 35,31 \\
\hline $\begin{array}{l}\text { Smear-negative and } \\
\text { culture-negative }\end{array}$ & 67 & 11.3 & 55 & 10,85 \\
\hline Other & 16 & 2.7 & 13 & 2,56 \\
\hline \multicolumn{5}{|l|}{ Tuberculosis involvement } \\
\hline Pulmonary & 405 & 68.4 & 362 & 71,40 \\
\hline Extrapulmonary & 71 & 12 & 54 & 10,65 \\
\hline Mixed & 44 & 7.4 & 36 & 7,10 \\
\hline Unknown & 72 & 12.2 & 55 & 10,85 \\
\hline
\end{tabular}

in either the emergency department or specialty clinics (Table 2).

On a bivariate level, the following variables were associated with unreported cases: age over 65 years, retirement, smoking history, immigrant status, normal or non-cavitary chest $x$-ray, smear-negative $\mathrm{TB}$, and the presence of extrapulmonary TB. On a multivariate level, the following variables were associated with unreported TB: retirement (OR: 3.04, CI 1.29-7.18), smear- negative TB (OR: 1.87, CI 1.07-3.28) and the presence of extrapulmonary TB (OR: 2.07, CI 1.05-4.09) (Tables 3 and 4). The percentage of reported cases among the smearpositive cases was $9.4 \%$ and $19.4 \%(\mathrm{p}=0.001)$ among the rest of the study population. Smear-positive TB was no associated to under-reporting.

\section{Discussion}

We found that $14.4 \%$ of TB cases were not reported to a public health department and the proportion of unreported cases ranged between 0 and $45.2 \%$ according to 
Table 3 Demographic characteristics of tuberculosis cases and factors associated with unreported cases

\begin{tabular}{|c|c|c|c|c|c|c|c|c|c|}
\hline & Total & Reported & & Unreported & & Bivariate analysis & & Multivariate analysis & \\
\hline & $N=592$ & $N=507$ & & $N=85$ & & OR (95 \% Cl) & $\mathrm{p}$-value & OR $(95 \% \mathrm{Cl})$ & $\mathrm{p}$-value \\
\hline Variables & & $n$ & $\%$ & $n$ & $\%$ & & & & \\
\hline \multicolumn{10}{|l|}{ Age (years) } \\
\hline $18-30$ & 146 & 128 & 87.7 & 18 & 12.3 & $1.19[0.62-2.27]$ & 0.592 & & \\
\hline $31-50$ & 237 & 212 & 89.5 & 25 & 10.5 & Ref. & Ref. & & \\
\hline $51-64$ & 62 & 52 & 83.9 & 10 & 16.1 & $1.64[0.71-3.56]$ & 0.238 & & \\
\hline$>65$ & 121 & 92 & 76 & 29 & 24 & $2.66[1.48-4.84]$ & 0.001 & & \\
\hline Unknown & 26 & 23 & 88.5 & 3 & 11.5 & $1.15[0.25-3.66]$ & 0.835 & & \\
\hline \multicolumn{10}{|l|}{ Sex } \\
\hline Male & 368 & 321 & 87.2 & 47 & 12.8 & Ref. & Ref. & & \\
\hline Female & 214 & 179 & 83.6 & 35 & 16.4 & 1.34 [0.83-2.14] & 0.235 & & \\
\hline Unknown & 10 & 7 & 70 & 3 & 30 & $3.00[0.59-11.5]$ & 0.165 & & \\
\hline \multicolumn{10}{|l|}{ Employment } \\
\hline Employed & 205 & 174 & 84.9 & 31 & 15.1 & $1.54[0.70-3.7]$ & 0.296 & $1.75(0.74-4.09)$ & 0.197 \\
\hline Unemployed & 184 & 169 & 91.8 & 15 & 8.2 & $0.77[0.32-2.02]$ & 0.581 & $0.88(0.35-2.23)$ & 0.801 \\
\hline Retired & 125 & 94 & 75.2 & 31 & 24.8 & 2.84 [1.27-7.04] & 0.01 & $3.04(1.29-7.18)$ & 0.011 \\
\hline $\begin{array}{l}\text { Unknown/On } \\
\text { disability }\end{array}$ & 78 & 70 & 89.7 & 8 & 10.3 & Ref. & Ref. & & Ref. \\
\hline \multicolumn{10}{|l|}{ Living situation } \\
\hline With family & 423 & 371 & 87.7 & 52 & 12.3 & Ref. & Ref. & & \\
\hline Alone & 42 & 33 & 78.6 & 9 & 21.4 & $1.96[0.84-4.21]$ & 0.116 & & \\
\hline In a group & 64 & 53 & 82.8 & 11 & 17.2 & 1.49 [0.70-2.96] & 0.287 & & \\
\hline Homeless & 14 & 11 & 78.6 & 3 & 21.4 & $2.01[0.42-6.81]$ & 0.338 & & \\
\hline Incarcerated & 10 & 8 & 80 & 2 & 20 & $1.88[0.25-7.95]$ & 0.477 & & \\
\hline Unknown & 39 & 31 & 79.5 & 8 & 20.5 & $1.86[0.76-4.12]$ & 0.166 & & \\
\hline \multicolumn{10}{|l|}{ Center of diagnosis } \\
\hline $\begin{array}{l}\text { Emergency } \\
\text { Department. }\end{array}$ & 320 & 283 & 88.4 & 37 & 11.6 & Ref. & Ref. & & \\
\hline Primary care & 113 & 94 & 83.2 & 19 & 16.8 & 1.55 [0.83-2.80] & 0.163 & & \\
\hline Specialty clinic & 91 & 76 & 83.5 & 15 & 16.5 & $1.52[0.77-2.87]$ & 0.223 & & \\
\hline Unknown or other & 68 & 54 & 79.4 & 14 & 20.6 & 1.99 [0.98-3.88] & 0.058 & & \\
\hline \multicolumn{10}{|l|}{ Country of origin } \\
\hline Spain & 401 & 334 & 83.3 & 67 & 16.7 & Ref. & Ref. & & \\
\hline Other & 191 & 173 & 90.6 & 18 & 9.4 & 0.52 [0.29-0.89] & 0.016 & & \\
\hline
\end{tabular}

healthcare facility. It is notable that the five healthcare facilities that reported $100 \%$ of their TB cases to the public health department employed a nurse case manager who acted as a liaison between the medical team and the infection control team, assisted with data collection, contact tracing, and case reporting to the public health department.

Previous studies in Europe have estimated the rate of unreported TB cases is over $20 \%$ [7, 10, 11, 18, 19]. A rate of $27 \%$ was described in central Italy [10], 38-49\% in the United Kingdom [7], and $80 \%$ in Greece [11]. Studies from Spain estimate rates of unreported TB range from
$20 \%$ to $46 \%[13-15,19]$, but these percentages represent a limited geographical area (the Baleares Islands, Area 15 of Alicante, León and Asturias). This range is wide and may be due to the local TB organization.

Regarding the factors associated with unreported TB cases, studies have described high rates of unreported cases among older patients [10,13], among those without microbiological confirmation [10], among patients with absence of cavitary lesions on chest x-ray [10, 13], and among non-immigrant patients [13]. Our study showed the same results on a bivariate level, but without statistical significance on a multivariate level for age, $\mathrm{x}$-ray 
Table 4 Clinical characteristics of tuberculosis cases and factors associated with unreported cases

\begin{tabular}{|c|c|c|c|c|c|c|c|c|c|}
\hline & Total & Reported & & Unreported & & Bivariate analysis & & Multivariate analysis & \\
\hline & $N=592$ & $N=507$ & & $N=85$ & & OR $(95 \% \mathrm{Cl})$ & $p$-value & OR (95 \% Cl) & p-value \\
\hline Variables & & $n$ & $\%$ & $\mathrm{n}$ & $\%$ & & & & \\
\hline \multicolumn{10}{|l|}{ Smoking } \\
\hline Non-smoker & 318 & 272 & 85.5 & 46 & 14.5 & 1.64 [0.94-3.00] & 0.084 & & \\
\hline Smoker & 194 & 176 & 90.7 & 18 & 9.3 & Ref. & Ref. & & \\
\hline Ex-smoker & 80 & 59 & 73.8 & 21 & 26.3 & $3.46[1.72-7.03]$ & 0.001 & & \\
\hline \multicolumn{10}{|l|}{ Alcohol use } \\
\hline Yes & 116 & 104 & 89.7 & 12 & 10.3 & Ref. & Ref. & & \\
\hline No & 467 & 395 & 84.6 & 72 & 15.4 & $1.56[0.84-3.14]$ & 0.162 & & \\
\hline Unknown & 9 & 8 & 88.9 & 1 & 11.1 & 1.20 [0.04-7.67] & 0.877 & & \\
\hline \multicolumn{10}{|l|}{ HIV status } \\
\hline Positive & 25 & 23 & 92 & 2 & 8 & Ref. & Ref. & & \\
\hline Negative & 446 & 384 & 86.1 & 62 & 13.9 & 1.74 [0.49-11.9] & 0.435 & & \\
\hline Not known by patient & 110 & 91 & 82.7 & 19 & 17.3 & 2.25 [0.59-16.2] & 0.264 & & \\
\hline Unknown & 11 & 9 & 81.8 & 2 & 18.2 & $2.48[0.23-27.0]$ & 0.431 & & \\
\hline \multicolumn{10}{|l|}{ Previous tuberculosis treatment } \\
\hline No & 543 & 464 & 85.5 & 79 & 14.5 & Ref. & Ref. & & \\
\hline Yes & 34 & 29 & 85.3 & 5 & 14.7 & $1.04[0.34-2.56]$ & 0.942 & & \\
\hline Unknown & 15 & 14 & 93.3 & 1 & 6.7 & $0.48[0.02-2.42]$ & 0.436 & & \\
\hline \multicolumn{10}{|l|}{ Drug resistance } \\
\hline No & 579 & 496 & 85.7 & 83 & 14.3 & Ref. & Ref. & & \\
\hline Yes & 13 & 11 & 84.6 & 2 & 15.4 & $1.15[0.16-4.47]$ & 0.861 & & \\
\hline \multicolumn{10}{|l|}{ Chest radiograph } \\
\hline Abnormal with cavitation & 208 & 191 & 91.8 & 17 & 8.2 & Ref. & Ref. & & \\
\hline Abnormal without cavitation & 284 & 235 & 82.7 & 49 & 17.3 & $2.33[1.32-4.29]$ & 0.003 & & \\
\hline Normal & 71 & 57 & 80.3 & 14 & 19.7 & $2.75[1.25-5.96]$ & 0.012 & & \\
\hline Unknown & 29 & 24 & 82.8 & 5 & 17.2 & $2.37[0.71-6.72]$ & 0.149 & & \\
\hline \multicolumn{10}{|l|}{ Microbiology } \\
\hline Smear-positive & 287 & 260 & 90.6 & 27 & 9.4 & Ref. & Ref. & & Ref. \\
\hline $\begin{array}{l}\text { Smear-negative and } \\
\text { culture-positive }\end{array}$ & 222 & 179 & 80.6 & 43 & 19.4 & $2.30[1.38-3.91]$ & 0.001 & $1.87(1.07-3.28)$ & 0.028 \\
\hline $\begin{array}{l}\text { Smear-negative and } \\
\text { culture-negative }\end{array}$ & 67 & 55 & 82.1 & 12 & 17.9 & $2.11[0.97-4.36]$ & 0.059 & $1.59(0.68-3.72)$ & 0.280 \\
\hline Other & 16 & 13 & 81.3 & 3 & 18.8 & $2.29[0.48-7.80]$ & 0.264 & $1.24(0.30-5.06)$ & 0.759 \\
\hline \multicolumn{10}{|l|}{ Tuberculosis involvement } \\
\hline Pulmonary & 405 & 362 & 89.4 & 43 & 10.6 & Ref. & Ref. & & Ref. \\
\hline Extrapulmonary & 71 & 54 & 76.1 & 17 & 23.9 & 2.65 [1.38-4.94] & 0.004 & $2.07(1.05-4.09)$ & 0.035 \\
\hline Mixed & 44 & 36 & 81.8 & 8 & 18.2 & 1.89 [0.77-4.18] & 0.156 & $1.50(0.63-3.53)$ & 0.353 \\
\hline Unknown & 72 & 55 & 76.4 & 17 & 23.6 & 2.61 [1.36-4.84] & 0.005 & $2.01(0.97-4.15)$ & 0.059 \\
\hline
\end{tabular}

HIV: Human immunodeficiency virus

findings or country of origin. Retirement was associated with a higher risk of under-reporting, even independent of age. This has also been demonstrated in studies performed in other countries [20], which describe $25 \%$ of unreported cases among patients over 60 years of age. This may be due to the higher rate of comorbidity conditions and multiple reasons for hospital admission, which could distract the provider that would diagnose and report the TB case.

We also found an association between unreported cases and extrapulmonary TB and smear-negative TB, for which 
the diagnosis may be delayed or without microbiological histology or culture. This was also described in many other studies [7, 10, 13, 20,21], and maybe due to the fact that the provider think that transmission is lower among these cases. Nonetheless, reporting TB cases to the public health department is important to identify affected patients promptly thereby lowering transmission, to calculate an accurate incidence, and also to identify the TB index cases.

Smear-positive TB patients are more contagious and thus case reporting and contact tracing is crucial. Our study found that $9.4 \%$ of smear-positive cases were not reported, which is actually lower than rates described in other studies [19].

The majority of the cases were diagnosed and reported from emergency departments and specialty clinics in our study as well as from other published studies $[13,15]$, and half of which were diagnosed in the emergency department. Case detection in the primary care setting is essential for early diagnosis and eventual disease control. We found that the diagnosis of TB in primary care centers is not associated with underreporting (Table 3), which differs from one Spanish study [13]. However the percentage of TB cases diagnosed in primary centers is small and could represent an initial opportunity for diagnosis that was missed. This suggests disease control in the primary care setting may be weak and could be a target for strategies to improve TB diagnosis. Training programs for the diagnosis of TB targeting the general public and primary care providers should be implemented.

When TB is not diagnosed or unreported, an opportunity to prevent disease transmission is lost and the disease can spread. All patients with a concern for TB should be immediately evaluated and the diagnosis should be reported to the public health department without delay $[5,6]$. This requires coordination between the hospital, the department of epidemiology, and the microbiology and pathology departments. For example, electronic reporting systems, in which case reports are sent electronically from local to centralized databases, have been implemented in other countries [22, 23].

Our study also has limitations that are inherent to retrospective studies because of missing information. However, a prospective study design could have led to a bias of high compliance and reporting. The large number of participating healthcare facilities in our study offers a good estimation of unreported TB cases, even with a retrospective design. Additionally, the number of patients who were not evaluated at a specialty clinic is low. The patients who were diagnosed and followed by primary care centers have microbiological data recorded in a microbiology registry compiled with data from specialty clinics, but no electronic medical record.

\section{Conclusions}

It is important that $\mathrm{TB}$ Control Programs encourage thorough case reporting to improve disease control, contact tracing and accuracy of epidemiological data. This is particularly relevant for TB cases that are smear-negative, given the association with under-reporting. As seen from our study results, the help from a TB nurse case manager could improve the rate of under-reporting.

\section{Additional file}

Additional file 1: Ethics. (DOCX $10 \mathrm{~kb}$ )

\section{Competing interests}

The authors declare that they have no competing interests.

\section{Authors' contributions}

CMG conceived of the study, and participated in its design and coordination, acquisition of data, interpreted data analysis and drafted the manuscript. CMG, TR, MG-C, AM, PB, FC, MS, CM, AP, CH, MC, JAC and The Working Group on Under-reporting of Tuberculosis in Spain participated in the acquisition of data and have been involved in revising the manuscript. $M C$ participated in the design of the study and performed the statistical analysis. JAC and TR participated in its design and coordination, interpreted data analysis and helped to draft the manuscript. All authors read and approved the final manuscript. The Working Group on Under-reporting of Tuberculosis in Spain: F. Álvarez (Hospital San Agustín, Avilés, Asturias), M. Barrón (Complejo Hospitalario San Millán-San Pedro, Logroño), P. Bermúdez (Hospital Universitario Carlos Haya, Málaga), A. Bustamante (Hospital Sierrallana, Torrelavega), M. Casals (Agencia de Salud Publica, Barcelona), F. Casas (Hospital Universitario San Cecilio, Granada), X. Casas (Hospital de Sant Boi, Llobregat), J.A. Caylá (Agencia de Salud Publica, Barcelona), A.E. Delgado (Hospital Santa Ana, Motril), M.M. García-Clemente (Hospital Central de Asturias, Oviedo), J.M. García-García (Hospital San Agustín, Avilés, Asturias), F.J. Garros (Hospital Santa Marina, Bilbao), J.A. Gullón (Hospital San Agustín, Avilés, Asturias), C. Hidalgo (Hospital Universitario Virgen de las Nieves, Granada), G. Jiménez (Hospital de Jaén), M. Marín (Hospital General de Castellón), C. Milá (Unitat de Prevenció i Control de Tuberculosis, Barcelona), C. Morales-García (Hospital Universitario Virgen de las Nieves, Granada), V. Moreno (Hospital Carlos III, Madrid), A. Muñoz (Hospital Universitario Carlos Haya, Málaga), A. Penas (Complejo Hospitalario Xeral-Calde, Lugo), J. Rodríguez (Hospital Universitario Virgen de las Nieves, Granada), T. Rodrigo (Fundación Respira de SEPAR, Barcelona), M. Somoza (Consorcio Sanitario de Tarrasa, Barcelona), M.E. Valencia (Hospital Carlos III, Madrid), M.A. Villanueva (Hospital San Agustín, Avilés, Asturias).

\section{Acknowledgements}

We would like to acknowledge the Public Health Departments of Andalusia, Asturias, Cantabria, Catalonia, Galicia, The Rioja, Madrid, The Basque Country, and Valencia, and the Preventive Medicine Departments of participating hospitals who made significant contributions in the acquisition of data. We would also like to thank to Jeanne Gambucci for her role as the scientific medical writer.

The present study was carried out at the Integrated TB Program (PII TB) of the Spanish Society of Lung Pathology (SEPAR) and was financed by a SEPAR research grant.

\section{Author details}

${ }^{1}$ Programa Integrado de Investigación en Tuberculosis (PII-TB) de la Sociedad Española de Neumología y Cirugía Torácica (SEPAR), Barcelona, Spain.

${ }^{2}$ Hospital Universitario Virgen de las Nieves de Granada, Granada, Spain. ${ }^{3}$ Fundación Respira de la SEPAR, Barcelona, Spain. ${ }^{4}$ Hospital Central de Asturias de Oviedo, Oviedo, Spain. ${ }^{5}$ Hospital Universitario Carlos Haya de Málaga, Malaga, Spain. ${ }^{6}$ Hospital Universitario San Cecilio de Granada, Granada, Spain. ${ }^{7}$ Consorcio Sanitario de Tarrasa, Barcelona, Spain. ${ }^{8}$ Unitat de 
Prevenció i Control de Tuberculosis de Barcelona, Barcelona, Spain. ${ }^{9}$ Hospital Xeral-Calde de Lugo, Lugo, Spain. ${ }^{10}$ Agencia de Salud Publica, Barcelona, Spain. ${ }^{11}$ CIBER de Epidemiologia y Salud Pública (CIBERESP), Barcelona, Spain.

Received: 28 December 2014 Accepted: 21 July 2015

Published online: 29 July 2015

\section{References}

1. WHO: Global Tuberculosis Report 2014. World Health Organization. WHO/HTM/TB 2014. Available: http://www.who.int/tb/publications/ global_report/en/.

2. European Centre for Disease Prevention and Control (ECDC)/World Health Organization Regional Office for Europe: Tuberculosis surveillance and monitoring in Europe 2014. Stockholm, 2014. Available: http:// www.euro.who.int/ data/assets/pdf file/0004/245326/Tuberculosissurveillance-and-monitoring-in-Europe-2014.pdf?ua=1. Accessed 2014 Jun 10

3. Orcau A, Caylà J, Martínez JA. Present epidemiology of tuberculosis. Prevention and control programs. Enferm Infecc Microbiol Clin. 2011;29(Supl 1):2-7.

4. Rodríguez E, Villarrubia S, Díaz O, Hernández G, Tello O. Situación de la tuberculosis en España. Casos de tuberculosis declarados a la Red Nacional de Vigilancia Epidemiológica en,2010. Bol Epidemiol Sem. 2012;20(3):26-41. Available: http://www.revista.isciii.es/index.php/bes/ article/download/693/727 Accessed 2014 Jun 11

5. CDC. Trends in tuberculosis United States, 2008. MMWR. 2009;58:249-53.

6. CDC. Decrease in Reported Tuberculosis Cases — United States, 2009 MMWR. 2010;59:289-98.

7. Pillaye J, Clarke A. An evaluation of completeness of tuberculosis notification in the United Kingdom. BMC Public Health. 2003;3:31.

8. Theodoracopoulos P, Dimadi M, Constantopoulos SH. Calculation of new cases of tuberculosis from the consumption of antituberculosis medications; comparison with notification rates. Respiration. 1992;59(1):64.

9. Jelastopulu E, Alexopoulos EC, Venieri D, Tsiros G, Komninou G, Constantinidis TC, Chrysanthopoulos K. Substantial underreporting of tuberculosis in West Greece - implications for local and national surveillance. EuroSurveill 2009;14(11):pii = 19152. Available: http:// www.eurosurveillance.org/ViewArticle.aspx?Articleld=19152.

10. Melosini L, Vetrano U, Dente FL, Cristofano M, Giraldi M, Gabbrielli L, et al. Evaluation of underreporting tuberculosis in Central Italy by means of record linkage. BMC Public Health. 2012;12:472. Available: http://www.biomedcentral.com/1471-2458/12/472.

11. Lytras T, Spala G, Bonovas S, Panagiotopoulos T. Evaluation of tuberculosis underreporting in Greece through comparison with anti-tuberculosis drug consumption. PlosOne. 2012;7(11):e50033.

12. D'Ambrosio L, Centis R, Spanevello A, Migliori GB. Improving tuberculosis surveillance in Europe is key to controlling the disease. Euro Surveill 2010; 15 (11):pii = 19513. Available: http://www.eurosurveillance.org/ ViewArticle.aspx?Articleld=19513.

13. Giménez Duran J, Galmés Truyols AM, Guibert DH, Bonilla Vargas LA, Luque Fernández MA, Bosch $\mathrm{Cl}$, et al. Tuberculosis surveillance in the Balearic islands and characteristics of unreported cases from 2005 to 2007. Gac Sanit. 2011;25(1):84-6

14. Calpe JL, Chiner E, Marín J, Martínez C, López MM, Sánchez E. Tuberculosis notification from 1987 to 1999 for the public health area of the community of Valencia (Spain). Arch Bronconeumol. 2001;37:417-23.

15. Múñiz-González F, Guerra-Laso J, García-García S, López-Veloso M, Raposo-García S, Carracedo-Falagán N, et al. Estimate of the real incidence of tuberculosis in the Leon Health Area: Application of the capture-recapture method to compare two information sources. Enferm Infecc Microbiol Clin. 2013;31(2):82-7.

16. Altet Gómez MN, Alcaide Megías J. Control and elimination of tuberculosis in Spain: Recommendations for the twenty-first century. An Pediatr (Barc). 2006;64(1):66-73

17. WHO: Treatment of tuberculosis guidelines, 4th ed. Geneva, World Health Organization, 2010 (WHO/HTM/STB/2009.420). Available: http://whqlibdoc. who.int/publications/2010/9789241547833_eng.pdf. Accessed 2013 april 2.

18. Ködmön C, Hollo V, Huitric E, Amato-Gauci A, Manissero D. Multidrug- and extensively drug-resistant tuberculosis: a persistent problem in the European Union European Union and European Economic Area. Euro Surveill 2010; 15 (11):pii = 19519. Available: http://www.eurosurveillance.org/ ViewArticle.aspx?Articleld=19519.
19. Informe de la tuberculosis de Asturias (2007-2012). Available: http://www.astu rias.es/Astursalud/Ficheros/AS_Salud\%20Publica/AS_Vigilancia/ Informes\%20epidemiol\%C3\%B3gicos/2012_web.pdf.

20. Baussano I, Bugiani M, Gregori D, van Hest R, Borracino A, Raso R, et al. Undetected burden of tuberculosis in a low-prevalence area. Int J Tuberc Lung Dis. 2006;10:415-21.

21. Buiatti E, Acciai S, Ragni P, Tortoli E, Barbieri A, Cravedi B, et al. The quantification of tuberculosis disease in an Italian area and the estimation of underreporting by means of record linkage. Epidemiol Prev. 1998;22:237-41.

22. Rolfhamre P, Jansson A, Arneborn M, Ekdahl K. SmiNet-2. Description of an internet-based surveillance system for communicable diseases in Sweden. Euro Surveill. 2006;11(5):103-7.

23. Krause G, Altmann D, Faensen D, Porten K, Benzler J, Pfoch T, et al. SurvNet electronic surveillance system for infectious disease outbreaks, Germany. Emerg Infect Dis. 2007;13:1548-55.

\section{Submit your next manuscript to BioMed Central and take full advantage of:}

- Convenient online submission

- Thorough peer review

- No space constraints or color figure charges

- Immediate publication on acceptance

- Inclusion in PubMed, CAS, Scopus and Google Scholar

- Research which is freely available for redistribution 